ARTIGOS

\title{
Interpretação como des-ocultamento: contribuições do pensamento hermenêutico e fenomenológico-existencial para análise de dados em pesquisa qualitativa ${ }^{1,2}$
}

\section{Interpretation as de-concealment: contributions of hermeneutic and phenomenological-existential thought for data analysis in qualitative research}

\author{
Luciana Szymanski (i) \\ Heloisa Szymanski (ii) \\ Felipe Luis Fachim (iii)
}

(i) Pontifícia Universidade Católica de São Paulo - PUC-SP, São Paulo, SP, Brasil. http://orcid.org/0000-0002-1863-025X, lucianaszymanski@gmail.com.

(ii) Pontifícia Universidade Católica de São Paulo - PUC-SP, São Paulo, SP, Brasil. https://orcid.org/0000-0002-0579-8117, heloisa.szymanski@gmail.com.

(iii) Pontifícia Universidade Católica de São Paulo - PUC-SP, São Paulo, SP, Brasil. https://orcid.org/0000-0002-9658-3516, fefachim@gmail.com.

Resumo: Este artigo pretende refletir sobre procedimentos de análise e interpretação de dados em pesquisa nos campos da educação e da psicologia. O caminho que adotamos parte inicialmente de uma reflexão sobre o sentido da investigação e análise nas pesquisas qualitativas, em especial na perspectiva fenomenológico-existencial de Martin Heidegger e hermenêutica de Hans-Georg Gadamer, entendendo que existe um diálogo profícuo entre esses pensamentos, apesar de suas especificidades. Para que pudéssemos aprofundar a reflexão proposta, apresentamos, a título de exemplo, trechos de análise de uma pesquisa de cunho interventivo, realizada em parceria com uma instituição escolar, especificamente sobre o tema adolescência na escola, cujos procedimentos de interpretação e análise foram construídos alinhados às concepções epistemológicas propostas.

Palavras-chave: pesquisa qualitativa, fenomenologia, hermenêutica, psicologia, educação

\footnotetext{
1 Apoio: Conselho Nacional de Desenvolvimento Científico e Tecnológico (CNPq); Coordenação de Aperfeiçoamento de Pessoal de Nível Superior (Capes); Plano de Incentivo à Pesquisa (PIPEq) - Pontifícia Universidade Católica de São Paulo (PUC-SP); Plano de Incentivo à Pesquisa Aplicada à Docência (Pipad) - PUCSP.

${ }^{2}$ Normalização, preparação e revisão textual: Aline Maya (Tikinet) - aline@tikinet.com.br
} 


\section{pro.posıções}

http://dx.doi.org/10.1590/1980-6248-2018-0014

$e$-ISSN 1980-6248

Abstract: This article intends to reflect about the analysis and interpretation of research data in the fields of education and psychology. It brings initially a reflection about the meaning of investigation and analysis in qualitative research, especially in the phenomenological-existential perspective of Martin Heidegger and Hans Georg Gadamer's hermeneutics, once there is a fruitful dialogue between these thoughts, despite their specificity. We'll present, as an example, an interventive research, so that we can illustrate the proposed reflection, carried out in an educational institution, specifically about teenagers at school, whose procedures of interpretation and analysis were constructed according to the proposed epistemological conceptions.

Keywords: qualitative research, phenomenology hermeneutics, psychology, education

\section{Algumas reflexões sobre pesquisa qualitativa inspirada no pensamento fenomenológico}

Na década de 1980 observamos em teses e dissertações capítulos que justificavam a cientificidade da pesquisa qualitativa nas ciências sociais e humanas. Gradualmente, a investigação qualitativa tornou-se aceita no meio acadêmico, e essa discussão caiu em desuso em termos da disputa de espaço entre pesquisas qualitativas e quantitativas. Atualmente, alguns autores consideram as "batalhas epistemológicas entre pesquisadores qualitativos e quantitativos, entre uma diversidade de grupos de discussão interna e grupos externos, como polêmicas, verborrágicas e improdutivas" (Bauer \& Gaskell, 2013, p. 15). Surgiram diferentes formas de se realizarem pesquisas qualitativas, cujas contribuições para diversas áreas do conhecimento têm sido exploradas em textos sobre a temática (Denzin \& Lincoln, 2006; Flick, 2009), e a perspectiva fenomenológica, como um método, foi uma delas. Parece-nos pertinente a exposição do rigor desse método, especialmente por utilizar linguagens e procedimentos fundamentados em uma lógica não hegemônica ${ }^{3}$.

Amadeu Giorgi (1985) foi um dos iniciadores da prática da pesquisa qualitativa em psicologia segundo uma perspectiva fenomenológica, na década de 1970. Seus procedimentos

\footnotetext{
${ }^{3}$ Esse modo de refletir não hegemônico que sustenta o pensamento fenomenológico será considerado no item "Algumas considerações sobre o pensamento hermenêutico e suas repercussões no âmbito da pesquisa".
} 


\section{pro.posições}

$e$-ISSN 1980-6248

tornaram-se referência para a análise e a interpretação de dados e ofereceram fundamentação teórico-metodológica inspirada no pensamento de Edmund Husserl e Maurice Merleau-Ponty. A pesquisa qualitativa fundamentada na perspectiva fenomenológica e, especificamente, na fenomenológico-existencial - entendendo essa perspectiva como aquela que se inspira no pensamento de Martin Heidegger - desenvolveu-se posteriormente, permitindo, assim, a elaboração de outros procedimentos de análise e interpretação, como os que aqui abordaremos mais adiante. Uma das contribuições do pensamento fenomenológico-existencial é sobre aquilo que entendemos na pesquisa como "dado", ou aquilo que se mostra no contexto de investigação. O termo "dado" pode nos remeter a uma lógica investigativa que entende resultado como algo que está ali, "doado", existindo independentemente de quem o vê. $\mathrm{Na}$ perspectiva fenomenológico-existencial, algumas considerações podem ser feitas sobre o sentido estático, impermeável e uno do "dado". Nesse olhar, os "dados" referem-se ao fenômeno que se mostrou a quem pesquisa e têm relação com a pergunta inicial da investigação em questão. Tal pergunta, por sua vez, traz à tona uma inquietação de quem pesquisa, uma questão:

\footnotetext{
Questões são próprias do humano, enquanto produtor de sentido, por sua condição de ser comunicacional. Nessa perspectiva, as inquietações experimentadas pelo pesquisador referemse a alguma dimensão de sua existência, refletindo um não saber (-se) por inteiro: a pessoa se mobiliza por questões que a colocam diante da impossibilidade (ainda que momentânea) de compreender algo que lhe diz respeito ou implica de alguma forma. (Cabral \& Morato, 2013, p. 160)
}

Como lembra Critelli (1996), "a fenomenologia ... subordina a possibilidade de conhecimento às possibilidades existenciais" (p. 16). Nas palavras da autora, "mais do que ponderar a respeito de instrumentais, o delineamento de uma metodologia de investigação e análise fundada na fenomenologia deverá cuidar do talhamento de um olhar" (Critelli, 1996, p. 16, grifo da autora). O que se constitui como "dado" na pesquisa fenomenológico-existencial é a manifestação do fenômeno que se deseja compreender sob um olhar específico. O que caracteriza esse olhar? Já se indicaram acima duas características desse olhar: a condição de abertura para o novo e o diferente, assim como para a necessidade de se reconhecer "o que" e "como" o fenômeno em questão se mostra para quem pesquisa.

Tal olhar traz consigo tanto uma concepção de existência humana como de conhecimento e de verdade, as quais fundamentarão a pergunta e a análise no seu caráter 


\section{pro.posições}

http://dx.doi.org/10.1590/1980-6248-2018-0014

$e$-ISSN 1980-6248

interpretativo. Como quer Heidegger (2012), “em todo entender de mundo está coentendida a existência e o inverso. Toda interpretação se move, além disso, na estrutura já caracterizada do prévio. Toda interpretação que deva contribuir para o entendimento já deve ter entendido aquilo por interpretar" (p. 431). No caso da pesquisa, que é nosso foco, sabemos que sua sistematização - independentemente dos procedimentos utilizados - é comunicada na linguagem textual; portanto, a escrita e a leitura deste texto se dão via interpretação. Referir-se à interpretação nos remete à hermenêutica gadameriana, foco de interesse deste artigo na sua possibilidade de contribuição para falarmos de pesquisa.

\section{Algumas considerações sobre o pensamento hermenêutico e suas repercussões no âmbito da pesquisa}

Uma das origens da palavra "hermenêutica" refere-se ao deus Hermes, "mensageiro divino, aquele que transmite as mensagens dos deuses aos homens" (Gadamer, 2002a, p. 112), ou seja, traduzir para uma linguagem mais próxima da experiência das pessoas algo que se apresentou de modo estranho e obscuro. Gadamer traz como uma característica da hermenêutica a condição de transitar entre mundos diferentes, de deuses e homens, ou entre pessoas que falam idiomas diferentes ou vêm de culturas e experiências diversas.

Para esse autor (Gadamer, 2002a), a hermenêutica está associada ao fenômeno da compreensão e se apresenta como uma racionalidade que se contrapõe à das ciências físicas tradicionais. Segundo Hermann (2003), a hermenêutica responde "à exigência de se contrapor a uma época que procurou conhecer seguindo apenas a racionalidade de procedimentos empírico-formais e da explicação causal, própria das ciências naturais” (p. 14). Trata-se de outra possibilidade de conhecimento, cujo caráter é interpretativo, que leva em conta a subjetividade, a historicidade e a relatividade de uma verdade temporalmente condicionada, e que aceita contribuições de outras áreas do conhecimento, como a arte (Hermann, 2003).

Gadamer (2002b) afirma que:

O problema hermenêutico adquiriu uma nova ênfase na esfera da lógica das ciências sociais pois, ... à medida que a sociedade possui sempre uma existência compreendida no âmbito da linguagem, o próprio campo de objetos das ciências sociais é presidido pela dimensão hermenêutica. (p. 138) 


\section{pro.posıções}

http://dx.doi.org/10.1590/1980-6248-2018-0014

$e$-ISSN 1980-6248

Ricoeur (1978) aponta para o fato de que a intenção e o fundamento são compreendidos sempre em um tempo e em uma cultura determinados, com influências de tradições e correntes de pensamento. $\mathrm{O}$ autor explicita a interpretação como "O trabalho de pensamento que consiste em decifrar o sentido oculto no sentido aparente, em desdobrar os níveis de significação implicados na significação literal” (Ricoeur, 1978, p. 15). Dessa forma, falar sobre hermenêutica é, de algum modo, apontar o caráter fluido e contextualizado da interpretação, o que nos leva necessariamente a uma reflexão sobre a verdade. Neste caso, apontamos para a verdade dos dados, ou a verdade dos resultados de uma pesquisa, por exemplo, que, no seu formato de texto, traz sempre implicados o "sentido oculto e o sentido aparente" para que possam ser explicitados.

\section{Entrelaçamentos do pensamento fenomenológico e hermenêutico: contribuições para o processo investigativo}

Neste item, abordaremos o entrelaçamento dessas duas vertentes de pensamento que inspiram nosso modo de pesquisar, sobretudo o momento da análise. Iniciamos, assim, com suas interfaces para seguirmos com suas especificidades.

De acordo com Heidegger (2012), a fenomenologia não é e nem jamais poderá ser uma "corrente" (Richtung).

A expressão "fenomenologia" tem a significação primária de um conceito-de-método [Methodenbegriff]. Não caracteriza o quê de conteúdo-de-coisa [sachhaltige], mas o seu como.... O termo "fenomenologia" exprime uma máxima que pode ser assim formulada: "às coisas mesmas", em oposição a todas as construções que flutuam no ar, aos achados fortuitos, à assunção de conceitos só em aparência demonstrados, às perguntas só aparentemente feitas e que são transmitidas ao longo de gerações como "problemas".... "Fenomenologia" não nomeia o objeto de suas pesquisas, nem caracteriza o seu conteúdo-de-coisa [Sachhaltigkeit]. A palavra só informa sobre o como do mostrar e o modo de tratar aquilo de que se deve tratar nessa ciência" (pp. 101, 119, grifo do autor)

Fenomenologia e hermenêutica entrelaçam-se numa relação descrita por Grondin (2003) como a virada hermenêutica da fenomenologia e, mais tarde, a virada fenomenológica da hermenêutica. Grondin (2003) refere-se à "contribuição silenciosa de Husserl à hermenêutica" (p. 19); apoiando-se em Gadamer, o autor expõe que a grande descoberta da fenomenologia foi a da intencionalidade, o que significa que, para Husserl, a consciência é sempre consciência de 


\section{pro.posições}

$e$-ISSN 1980-6248

algo. Grondin (2003) informa que "o termo intenção provém da tradição hermenêutica. A intenção (no sentido de, por exemplo, intentio auctoris ou do scopus) designa, com efeito, o sentido de um texto, de uma frase, o sentido que há nas, mas também por trás das palavras" (p. 8, tradução nossa). Para Grondin, a chamada às coisas mesmas por Husserl refere-se ao caminho das palavras às coisas mesmas, como a busca da intencionalidade, o que é um processo hermenêutico.

Ao considerar a virada hermenêutica da fenomenologia, Grondin (2003) apresenta o seguinte questionamento, que aponta para o que esse autor denomina de aporia temática da fenomenologia:

o que se deve fazer ver na fenomenologia? As coisas mesmas? Certamente, mas isto não tem sentido ao se pressupor que as coisas mesmas são antes e mais frequentemente recobertas ou desviadas [detournées]. É, portanto, esse desvio que deve se tornar perceptível e explicado. (p. 5, tradução nossa)

Para Grondin (2003), o verdadeiro artesão da virada hermenêutica foi Heidegger, o primeiro a se aperceber da "aporia temática" da fenomenologia, que expõe o problema de como voltar às coisas mesmas sem se prender à "mera descrição", ou ao que Grondin (2003) chama de "descrição insípida" (p. 15). Segundo ele, Heidegger insiste que é preciso "iluminar fenomenologicamente $o$ que não se mostra, mas que exige ser trazido à fenomenalidade porque constitui o sentido e o fundamento de tudo o que se mostra" (Grondin, 2003, p. 15, grifo do autor). Para se trazer à luz o que não se mostra, a interpretação é necessária. Trata-se de uma desconstrução do encobrimento pela intervenção hermenêutica.

Grondin (1999), referindo-se ao pensamento tardio de Heidegger, entende que, "a partir de sua práxis de interpretação, [Heidegger] permaneceu inteiramente hermenêutico" (p. 176, grifo do autor). Ao esclarecer o significado de hermenêutico para Heidegger, diz Grondin (1999) que "o hermenêutico expressa a trazida de uma mensagem que desperta um escutar. Em parte alguma esteve Heidegger tão perto da tradição hermenêutica como aqui” (p. 177).

Para Gadamer (2002a),

A tarefa hermenêutica se converte por si mesma num questionamento pautado na coisa e já se encontra sempre determinada por este. Com isto o empreendimento hermenêutico ganha um solo firme a seus pés.... Quem quer compreender um texto, em princípio, tem que estar disposto a deixar que ele diga alguma coisa por si. (p. 405) 


\section{pro.posıções}

http://dx.doi.org/10.1590/1980-6248-2018-0014

$e$-ISSN 1980-6248

Grondin (2003) chama de "virada fenomenológica da hermenêutica" (p. 84) o elemento crítico que desobstrui a fenomenologia, uma vez que as coisas não são simples e estão encobertas. Por outro lado, "uma hermenêutica sem a fenomenologia fica vazia" (Grondin, 2003, p. 86). A fenomenologia não é "nem o título de um método, nem de um domínio de objetos, mas é antes de tudo uma virtude: é fenomenológico o olhar (ou o discurso) que dá conta de fazer falar (ou ver) os fenômenos" (Grondin, 2003, p. 99).

Foram esses fundamentos que inspiraram nossos projetos de pesquisa qualitativa na perspectiva fenomenológico-existencial e hermenêutica. Mas o que é investigar na consideração desses fundamentos? Critelli (1996) considera uma investigação como "todo querer saber, querer compreender que se lança interrogante em direção àquilo que o apela, que o afeta, que provoca sua atenção e interesse" (p. 25, grifo da autora). Conforme lembra a autora (Critelli, 1996), na investigação fenomenológico-existencial interroga-se o que é e como é algo, isto é, o que e como algo se apresenta - busca-se algo que irá se mostrar situado em um mundo, na singularidade de seu modo de aparecer. Aparecer, manifestar-se, é "uma exposição, um mostrar-se do ente, um trazer-se à luz para um olhar" (Critelli, 1996, p. 54) diante de alguém que seja capaz de compreender o que se manifesta. Quem recepciona a manifestação somos nós, na nossa singularidade e na coexistência com os outros no mundo, em um determinado tempo e lugar. Segundo essa perspectiva, o que aparece não o faz de modo idêntico para diferentes pessoas.

$\mathrm{Na}$ tentativa de ilustrar esse movimento compreensivo, recorremos ao universo musical, em que as mesmas notas tocadas podem ser acordes diferentes, dependendo de como são nomeados: um dó maior pode ser lido como um ré duplo bemol maior, por exemplo. Ou ainda, mudando de contexto, se nos debruçarmos na questão da utilização do espaço urbano, um mesmo terreno é uma possibilidade de moradia para uns, e de especulação imobiliária (portanto, de enriquecimento) para outros, aparecendo, assim, com sentidos (e interesses) opostos: já não é, assim, o mesmo terreno. Ou seja, o que aparece não são meros objetos, coisas em si, mas fenômenos, que acontecem num universo de sentido ${ }^{4}$ e se somam à experiência e singularidade de quem ou da cultura que os vivencia. Os sentidos são, portanto, compartilhados por uma

\footnotetext{
${ }^{4}$ Entendido como "destinação" (Critelli, 1996 p. 98). O fenômeno se mostra na destinação que lhe foi dada pelas pessoas.
} 


\section{pro.posıções}

http://dx.doi.org/10.1590/1980-6248-2018-0014

$e$-ISSN 1980-6248

cultura, um grupo. É isso que a fenomenologia quer dizer quando nos remete à "coisa mesma", termo cunhado por Husserl que se refere à coisa em questão que aparece para alguém 5 .

Segundo essa perspectiva, é pela "coisa mesma" que interrogamos em uma pesquisa, sabendo que os fenômenos se mostram e se ocultam e dependem de como são vistos e compreendidos pelas pessoas em determinada circunstância. Inspirados nesse olhar, não temos acesso à totalidade do fenômeno, mas só podemos conhecer suas perspectivas, no nosso "horizonte existencial" (Critelli, 1996, p. 57). Quem pesquisa tem que estar atento às diferentes facetas do fenômeno e à sua possibilidade de ocultamento e revelação, lembrando que o fenômeno se insere sempre numa dimensão temporal. Essa atitude de abertura para o novo e o diferente (ou não), assim como para a própria experiência com o fenômeno estudado, é fundamental para a pesquisa e a prática em uma perspectiva fenomenológico-existencial. A tarefa de quem pesquisa é, portanto, desvelar o sentido que se abriu em um determinado encontro, o que coloca em questão a "verdade" do dado e a "verdade" do resultado, bem como refletir sobre alguns desdobramentos do termo "verdade" para ambos os olhares (o da fenomenologia existencial e da hermenêutica).

\section{A questão da verdade: um olhar fenomenológico-existencial e}

\section{hermenêutico}

A questão da verdade no campo da pesquisa é, portanto, fundamental: dialoga com aquilo que vem à tona no texto (ou discurso que se torna um texto ao ser transcrito) que chamamos de dado, ou seja, aquilo que aparece, bem como aquilo que se oculta. Como lembra Gadamer (2002b), o jogo do ocultamento e do aparecer ocorre tanto nas ações humanas como no discurso, que pode transmitir, além da "verdade", "a aparência, o engano e a simulação" (p. $60)$.

Foge de nossa competência e do escopo deste artigo a pretensão de retomar a trajetória do termo verdade ao longo da história; por outro lado, a noção de verdade é fundamental no pensamento que aqui utilizamos como fundamento metodológico e essencial na compreensão

\footnotetext{
${ }^{5}$ Estamos aqui nos referindo à palavra "Sache", explorada por Gadamer (2002b) em sua análise do termo original "coisa mesma"
} 


\section{pro.posıções}

http://dx.doi.org/10.1590/1980-6248-2018-0014

$e$-ISSN 1980-6248

do processo de pesquisa, desde a constituição da interrogação que a sustenta até a interpretação e análise dos seus dados. Por isso, seguiremos a perspectiva de Heidegger (2008), que entende que “esta palavra 'verdade' tão sublime e, ao mesmo tempo, tão gasta e embotada designa o que constitui o verdadeiro enquanto verdadeiro.... O verdadeiro é o efetivamente real" (pp. 190191).

Critelli (1996) nos lembra a indissociabilidade entre verdade e realidade na perspectiva fenomenológico-existencial. Esta escapa da visão essencialista de uma verdade única, universal e atemporal. Sem cair no senso comum, mas na consideração daquilo que Critelli (1996) chama de "relatividade da perspectiva", reconhece-se a "relatividade da verdade", sempre vista sob o prisma existencial. Essa autora explicita o movimento de realização, ou o tornar-se real de um fenômeno, quando ele:

é tirado de seu ocultamento por alguém ... acolhido e expresso através de uma linguagem ... é visto e ouvido por outros ... referendado como verdadeiro por sua relevância pública ... e, por fim, efetivado em sua consistência através da vivência afetiva e singular dos indivíduos. (Critelli, 1996, p. 69)

Para Heidegger (2008),

O verdadeiro, seja uma coisa verdadeira ou uma proposição verdadeira, é aquilo que está de acordo, o que concorda. Ser verdadeiro e verdade significam aqui "estar de acordo"; e isto de duas maneiras: por um lado, a consonância entre a coisa e o que dela previamente se presume, e, por outro lado, a concordância entre o que é visado pela enunciação e a coisa. (pp. 191-192)

Heidegger desenvolve a reflexão sobre a verdade buscando a origem grega do termo, alethéia, que significa desocultação. "Ser verdadeiro (verdade) significa ser-descobridor.... A alethéia ... significa 'as coisas elas mesmas', o que se mostra, o ente no Como de seu ser descoberto" (Heidegger, 2012, p. 607, grifo do autor).

Ora, o que se descobre, descobre-se em uma perspectiva, de modo que a verdade perde, na concepção fenomenológico-existencial, seu caráter de adequação a algum fato em si; não é mais aquilo que corresponde a um fato. Como nos lembra Lawn (2007), Gadamer "rejeita o discurso ortodoxo da verdade como correspondência, representação ou, como ficou conhecido, adequação" (p. 83). Gadamer (2002b) afirma que "há um nexo originário entre ser verdadeiro e discurso verdadeiro. A desocultação do ente vem à fala no desvelamento da proposição" (p. 60). É o discurso que deixa o desocultado se apresentar. Esse pensador refere-se inúmeras vezes à experiência da verdade, que não pode ser acessada com o instrumental técnico das ciências ditas 


\section{pro.posıções}

http://dx.doi.org/10.1590/1980-6248-2018-0014

$e$-ISSN 1980-6248

exatas. Isso obviamente não significa que não haja rigor na busca pela verdade que se dá segundo procedimentos orientados pela hermenêutica. É esse rigor que pretendemos resgatar neste artigo. A discussão sobre a verdade nos coloca diante de suas múltiplas possibilidades, o que aparece já no enunciado de uma pesquisa.

Para Gadamer (2002b) “não há nenhum enunciado que não seja uma espécie de resposta" (p. 67) a uma pergunta, além de apresentar pressupostos não expressos. Não é um processo fácil ver a pergunta a que um enunciado responde; é preciso compreender que o enunciado surge em uma "situação de pergunta", que inclui "a quem se diz algo com o enunciado" (Gadamer, 2002b, p. 68). Embora a questão do enunciado seja de alta complexidade, e sua discussão fuja do escopo deste texto, abordaremos como Gadamer (2002b) considera a interação entre pergunta e resposta da seguinte maneira:

Quando alguém faz uma afirmação que não compreendemos, procuramos saber como ele chegou a isso. Qual a pergunta que ele se fez para poder formular este enunciado como resposta? E se for um enunciado que deva ser verdadeiro, então nós mesmos temos que tentar formular a pergunta em relação à qual o enunciado quer ser uma resposta. Por certo, nem sempre é fácil encontrar $a$ pergunta a que o enunciado responde. (p. 67)

Gadamer (2002a) sugere que a dialética da pergunta e resposta possibilita que a "compreensão se manifeste como uma relação recíproca, semelhante a uma conversação" (p. 555). A conversação possibilita uma linguagem comum, e o "acordo na conversação não é uma mera representação e imposição do próprio ponto de vista, mas uma transformação rumo ao comum, de onde já não se continua sendo o que se era" (Gadamer, 2002a, p. 556). Essa afirmação aponta para o compreender, que não significa deslocar-se para dentro do outro - seja ele um texto ou uma pessoa com quem se conversa -, mas viver uma experiência. Gadamer (2002a) nos mostra que o resultado de uma conversação é algo novo e revelador, e se trata de um acontecimento que se dá nos interlocutores e que pode ser ou não uma boa experiência, porém é sempre reveladora, tem sua própria verdade e revela-se como uma "experiência de sentido" (p. 559).

Em muitos momentos, o autor afirma que o compreender é pôr-se de acordo, pela linguagem, com o outro, quer seja ele uma pessoa, um texto, uma obra de arte. Isso se dá mediante a adoção de uma atitude de atenção ao outro, de disposição de se colocar no seu lugar e considerar seus pontos de vista, o que vale dizer que é uma abertura para a alteridade e para o diálogo, que tem como pano de fundo a questão da compreensão. Esta nos permite apresentar 


\section{pro.posições}

$e$-ISSN 1980-6248

algumas especificidades do pensamento gadameriano que, inclusive, o afastam da fenomenologia existencial, conferindo-lhe um caráter específico, conforme será apresentado no item a seguir.

\section{Especificidades nas concepções de Heidegger e Gadamer: a questão}

\section{da compreensão}

Para Gadamer (2002a):

Compreender não é um ideal resignado da experiência de vida humana na idade avançada, mas tampouco, como em Husserl, um ideal metódico último da filosofia frente à ingenuidade do ir vivendo, mas ao contrário, é a forma originária de realização da pré-sença, que é ser-no-mundo ... a compreensão é o modo de ser da presença, na medida em que é poder-ser e "possibilidade". (p. 566 , grifos do autor)

Compreender se dá, portanto, no existir: "Compreender não significa mais um comportamento do pensamento humano dentre outros que se pode disciplinar metodologicamente, conformando assim um procedimento científico, mas perfaz a mobilidade de fundo da existência humana" (Gadamer, 2002b, p. 125). De fato, Gadamer identifica-se com a proposta de compreensão expressa por Heidegger, que para ele foi "o primeiro a cunhar o conceito de compreensão como uma determinação universal da pré-sença" (Gadamer, 2002a, p. 27), enfatizando seu caráter futural de projeto. Mas, à diferença de Heidegger, afirma: "Igualmente eu não quero negar que, dentro do contexto universal dos momentos da compreensão, eu destaquei, de minha parte, a direção para a apropriação do passado e o que vem pela tradição" (Gadamer, 2002a, p. 27).

Rohden (2012) lembra que, “embora o projeto filosófico gadameriano não seja compreensível nem factível sem a contribuição de Heidegger, ele possui especificidades e uma originalidade que precisa ser levada em conta quando nos adentramos no terreno da hermenêutica" (p. 16).

Ainda lembrando um afastamento da proposta heideggeriana, Gadamer não se propõe a desenvolver uma analítica da questão sobre o ser, mas uma "fenomenologia do acontecimento da compreensão" (Grondin, 2003, p. 77). 


\section{pro.posıções}

http://dx.doi.org/10.1590/1980-6248-2018-0014

\section{$e$-ISSN 1980-6248}

\section{Círculo hermenêutico}

Assim, a partir do entendimento de que compreender "perfaz a mobilidade de fundo da existência humana" (Gadamer, 2002b, p. 125), o processo compreensivo de um aprendizado, como o da própria linguagem que é adquirida por alguém que aprende uma nova língua, ou por uma criança aprendendo a falar, nos permite constatar que a compreensão prévia que se tem da língua nativa ou do repertório de fala até então adquirido pela criança permite a sistemática revisão do projeto prévio e da capacidade de projetar novos sentidos em outros usos, o que possibilita a compreensão de uma nova língua ou de novas palavras. Essa estrutura define o círculo hermenêutico que, para Gadamer (2002b), "significa que no âmbito da compreensão não se pretende deduzir uma coisa de outra, de modo que o erro lógico da circularidade da demonstração não é nenhum defeito de procedimento, mas representa a descrição adequada da estrutura do compreender" (p. 382).

Um outro aspecto da circularidade do fenômeno refere-se à regra hermenêutica, "segundo a qual devemos compreender o todo a partir do singular e o singular a partir do todo" (Gadamer, 2002b, p. 72). Gadamer refere-se ao processo de compreensão que segue a partir de antecipações de sentido, que são corrigidas conforme novas partes do todo são apreendidas, numa contínua ampliação das "unidades de sentido" em "círculos concêntricos" (Gadamer, 2002b, p. 72). Para se compreender um texto, o processo de projetar sentidos ocorre o tempo todo e, assim que uma parte é compreendida, define-se uma expectativa em relação ao todo do texto. Gadamer (2002a) chama de "projetos prévios" essas antecipações, que devem ser revisadas conforme se expande a compreensão do texto. Nesse processo, está-se exposto a erros, que devem ser corrigidos. O autor (Gadamer, 2002a) afirma que "a antecipação de sentido, na qual está entendido o todo, chega a uma compreensão explícita através do fato de que as partes que se determinam a partir do todo determinam, por sua vez, a esse todo” (p. 436). A concordância das partes com o todo indica a justeza da compreensão, o acordo entre as partes e o todo e a "participação em um sentido comum", o que é, em si mesmo, um critério de rigor metodológico (Gadamer, 2002a, p. 436). É com base nessa reflexão que pretendemos, no próximo item, apresentar de que modo o pensamento hermenêutico e fenomenológicoexistencial pode contribuir especificamente para o processo de análise de (trechos de) uma pesquisa, que aqui traremos a título de ilustração. 


\section{pro.posıções \\ $e$-ISSN 1980-6248}

http://dx.doi.org/10.1590/1980-6248-2018-0014

\section{A análise em foco: aproximando a discussão do processo de pesquisa}

O movimento circular entre as partes e o todo, a elaboração de projetos de sentido e o interrogar o texto são processos fundamentais no momento da análise de entrevistas, depoimentos, relatos de observação e demais textos resultantes dos procedimentos de pesquisa. Pode-se lembrar aqui da definição de análise encontrada no dicionário: "1. separação de um todo em seus elementos ou partes componentes; 2. estudo pormenorizado de cada parte de um todo, para conhecer melhor sua natureza, funções, relações, causas etc.” (Houaiss, 2001, p. 202). Acrescente-se a isso o trânsito entre as partes e o todo e as respostas aos questionamentos pelo sentido.

Veremos a seguir possibilidades de procedimentos de análise fundamentados nas ideias apresentadas. Traremos, para tanto, um exemplo de pesquisa que teve, como procedimento, a entrevista reflexiva (Szymanski \& Szymanski, 2014), de caráter aberto, sem roteiro prévio, que resultou, após sua transcrição, em um texto. Parte desse texto será trabalhada no próximo item na tentativa de fazer essa aproximação.

\section{Contextualizando a pesquisa}

Na pesquisa que aqui utilizaremos como ilustração (Szymanski, Amaral, \& Badan, no prelo), estudou-se o modo de ser adolescente em uma determinada escola para se lançar luz sobre aspectos dessa população e de sua relação com a instituição escolar. As questões investigadas à época foram "como a adolescência é compreendida em uma comunidade escolar?" e "como os adolescentes entendem o espaço escolar?". As respostas obtidas, frutos de uma investigação de cunho interventivo, que contou com idas sistemáticas à escola, inserção no território, entrevistas individuais e em grupo, bem como estudo cartográfico (Braga, Mosqueira, \& Morato, 2012), constituíram o texto final da pesquisa e apontaram para diversas compreensões: o adolescente pode ser aquele que desafia, que desobedece, que cria, que descuida, que inventa, que questiona a autoridade, que nos coloca diante do novo, que nos amedronta. A essas diferentes percepções correspondem muitos estados afetivos em relação aos jovens, por exemplo, de aceitação, temor, esperança, acolhimento, rejeição. Essa compreensão, atravessada por estados afetivos, remete a maneiras diferentes de agir e de conviver com esse grupo na escola - e fora dela -, como envolvê-lo em atividades comunitárias, limitar suas saídas 


\section{pro.posıções}

$e$-ISSN 1980-6248

http://dx.doi.org/10.1590/1980-6248-2018-0014

de casa ou oferecer espaço de reflexão sobre o mundo do trabalho, entre outras. Do ponto de vista dos adolescentes, a escola também se desdobra de várias maneiras, como espaço de acolhimento, de hostilidade e de possibilidade de aprendizado, conforme veremos adiante.

Todas as ações dessa pesquisa foram registradas em relatos, em textos que constituem o material de análise, contendo transcrição das falas, dados de observação e descrição de imagens. É a partir desse texto, mais particularmente do trecho de uma das entrevistas individuais, que a análise será realizada para responder à pergunta inicial da pesquisa. Nesse exemplo de pesquisa, quando se interroga pelo sentido de um fenômeno, a resposta deverá desvelar ações, disposições afetivas e concepções que se manifestaram a partir do trabalho analítico.

Com base nos textos escritos gerados pelos procedimentos, iniciamos o processo de análise com a leitura, ou, até antes, com a transcrição de dados gravados em áudio ou em vídeo. É como se fosse iniciada uma escuta inicial para se estabelecer uma conversação com o texto como um "outro", em que deve ser reconhecida sua alteridade e sua opinião ou, como diz Gadamer (2002b) sobre uma ideia, "tenho que tomar conhecimento, sem precisar compartilhála" (p. 404), e cuidar de não impor ao texto as próprias ideias e opiniões. Não se trata de desconsiderar tudo o que se sabe ou sente em relação ao tema, adotando uma pseudoneutralidade, mas sim de ter consciência de conhecimentos e opiniões prévias para desenvolver uma atitude de abertura para o que o texto quer dizer. Para trazer o texto à fala recorremos às perguntas que buscam a resposta latente no texto. Uma boa pergunta é aquela que se deixa interpelar pela “resposta latente”, como lembra Gadamer (2002a). É como procurar estabelecer uma conversação dialógica, seguindo a dialética da pergunta e resposta, com o sentido de inteirar-se sobre o que o texto fala.

O texto específico a ser considerado como ilustração neste artigo, como já dito anteriormente, é fruto de uma entrevista reflexiva, semiestruturada e dialógica com uma adolescente de 12 anos, aluna de uma escola municipal de ensino fundamental da cidade de São Paulo. Os pesquisadores - psicólogos - que analisaram essa entrevista partiram de suas posições, visões e conceitos prévios, construídos a partir de suas experiências de pesquisa naquela escola, de seus conhecimentos sobre psicologia e educação, de sua experiência clínica e psicoeducativa com adolescentes, e de sua própria experiência de vida com adolescentes e escolas. Essa reflexão sinalizou a alteridade do texto e provocou a curiosidade investigativa: "o que esta entrevista traz 


\section{pro.posıções}

http://dx.doi.org/10.1590/1980-6248-2018-0014

$e$-ISSN 1980-6248

de novidade para minha compreensão de adolescência e escola?”. Com essa postura, reconhecemos a alteridade do texto, o que define a abertura para o novo. A percepção de escola que irá se mostrar é desconhecida pela pesquisadora, diferente da dela; é uma escola que ela não conhece, pois é a escola vivida por uma adolescente de 12 anos. Não é preciso mudar a própria percepção, mas há que se permitir que a da jovem se mostre para os pesquisadores.

Ao ler o texto (no nosso caso, a entrevista), já antecipamos um primeiro sentido do todo, ou temos um projeto de sentido se constituindo na forma de projetos de compreensão, que devem ser anotados e verificados ao longo das leituras e releituras. O sentido da leitura flutuante é este: numa primeira "escuta", deixar emergirem projetos de sentido que dizem respeito à intenção do texto. O ponto de partida para a análise é orientar a vista para a "coisa mesma" que, neste caso, é o entendimento de adolescência na escola, e que se desvelará a partir da análise do texto resultante da fala da jovem entrevistada. É com esse texto que iniciaremos nossa conversação. Ele contém, ainda velado, oculto, o fenômeno que queremos desocultar. Agora é ao texto que lançaremos nossas interrogações pelo seu sentido: o que quer dizer? O que ela escolheu pinçar de sua experiência na escola para oferecer como resposta? Como diz Gadamer (2002b): “Todo enunciado tem pressupostos que ele não enuncia” (p. 67).

Vimos que o trabalho hermenêutico é o de antecipar projetos de sentidos, que deverão ser constantemente revisados conforme a conversação com o texto evolui. Nesse processo, somos sempre atravessados por opiniões e conhecimentos prévios. Ninguém começa a compreender como se fosse tábula rasa. O que a fenomenologia e a hermenêutica nos dizem é que precisamos reconhecer nossa posição prévia (vorbabe), visão prévia (vorsicht) e concepção prévia (vorbegriff) sobre o que nos propomos a analisar (Heidegger, 2012).

O modo de compreensão já dado é chamado por Heidegger (2012) de "ter-prévio" (Vorhabe), e não precisa ser apreendido "por uma interpretação temática" (p. 425). Já o "verprévio" (Vorsicht) funda-se no ponto de vista que "fixa aquilo em relação a que o entendido deva ser interpretado” (Heidegger, 2012, p. 425). “A interpretação se funda cada vez num 'ver-prévio' que 'recorta' no ter-prévio aquilo que fica sujeito a uma determinada interpretação" (Heidegger, 2012, p. 427). A interpretação também decide por uma determinada conceituação no processo, o que define o "conceito-prévio" (Vorbegriff). "A interpretação nunca é uma apreensão sempressupostos de algo previamente dado" (Heidegger, 2012, p. 427). 


\section{pro.posições}

$e$-ISSN 1980-6248

http://dx.doi.org/10.1590/1980-6248-2018-0014

Gadamer (2002a) afina-se com essa concepção de compreensão heideggeriana, porém enfatiza que "são os preconceitos não percebidos os que, com seu domínio, nos tornam surdos para a coisa de que nos fala a tradição" (p. 406). É essa ideia que retomamos adiante na análise de uma entrevista específica que aqui trazemos para ilustrar o processo de interpretação de uma narrativa: neste caso, registramos no processo elementos relativos ao olhar prévio do pesquisador como impressões que devem ser consideradas no processo investigativo, para se confirmarem ou não no conjunto da análise.

Como explicita Gadamer (2002a), "elaborar projetos corretos e adequados às coisas, que como projetos são antecipações que apenas devem ser confirmadas 'nas coisas', tal é a tarefa constante da compreensão" (p. 402). Daí a necessidade de se tomar conhecimento das próprias experiências e interpretações cotidianas prévias, tidas como óbvias. Para que isso ocorra, é necessário ter-se abertura para o novo, para o diferente e para o inesperado. Gadamer (2002a) se utiliza de uma expressão esclarecedora quanto ao cuidado de não impor opiniões prévias a um texto que se interpreta: "proteger um texto frente a mal-entendidos" (p. 404). Esse cuidado constitui o rigor que pauta o trabalho hermenêutico. Como nos lembra o autor, perguntar é mais difícil do que responder, e quem quiser compreender o texto deve estar preparado para que o texto lhe diga algo. A pergunta deve ter um sentido, colocar possibilidades e mantê-las em aberto. O filósofo esclarece que sentido aqui significa oferecer uma perspectiva ao interrogado. Gadamer (2002a) usa uma formulação bem ilustrativa para o ato de perguntar em uma conversação em que se queira explicar alguma coisa, que é: "romper essa coisa através de uma pergunta" (p. 535) e possibilitar a reflexão. "Para perguntar temos que querer saber, isto é, saber que não se sabe" (Gadamer, 2002a, p. 535) - a docta ignorantia socrática. Para esse autor, a verdadeira pergunta requer abertura, uma vez que não se fixa uma resposta, mas se desvela a "questionabilidade" do que se pergunta. É sair definitivamente do âmbito das certezas e das concepções já prontas. 


\section{pro.posıções}

http://dx.doi.org/10.1590/1980-6248-2018-0014

$e$-ISSN 1980-6248

\section{Conversando com o texto: análise de entrevista em foco}

Iniciamos, assim, a conversação com as partes e com o todo ${ }^{6}$ do texto. Apresentaremos no Quadro 1 um trecho com um exemplo dessa conversação, considerando partes da entrevista (falas da entrevistada): interrogações de sentido, possíveis respostas às interrogações e impressões do(a) entrevistador(a), na intenção de esclarecer para o leitor o movimento dialógico presente na análise de narrativas. Colocamos os trechos em um quadro no intuito de apresentar o movimento da análise de maneira mais explícita. Sabemos que toda tentativa de categorizar análises e interpretações de textos de pesquisas qualitativas, especialmente as que lidam com narrativas, como a nossa, corre o risco de apresentar dados de modo reducionista; assim, gostaríamos de explicitar que a característica classificatória dos quadros foi uma opção metodológica e de organização para este artigo, entendendo que aqui pretendemos mostrar um recorte do caminho que realizamos para a análise e que com isso não é possível explorar a complexidade dos itens que optamos elencar no Quadro 1, tais como as "interrogações de sentido", que são mais numerosas do que as aqui apresentadas, bem como as "possíveis respostas à interrogação" ou as "impressões", que podem ser articuladas entre si de múltiplas maneiras, como o foram na pesquisa original. Nossa pretensão, neste espaço de reflexão, é tornar visível o processo de diálogo com a narrativa que nos foi apresentada na entrevista em questão, entendendo que há, no que aparece, muitos elementos ocultos. Trata-se mesmo do processo de pesquisa que traz à luz aquilo que é possível para aquele pesquisador, naquele contexto.

Quadro 1 - Organização (didática) de um trecho de entrevista para análise

\begin{tabular}{|l|l|l|l|}
\hline $\begin{array}{c}\text { Falas da } \\
\text { entrevistada } \\
\text { (questões entre } \\
\text { colchetes) }\end{array}$ & $\begin{array}{c}\text { Interrogações de } \\
\text { sentido }\end{array}$ & $\begin{array}{c}\text { Impressões } \\
\text { Possíveis respostas à } \\
\text { interrogação }\end{array}$ & $\begin{array}{c}\text { Imperdade para } \\
\text { (libressar o conflito } \\
\text { expas novas } \\
\text { dampressões com o } \\
\text { conhecimento } \\
\text { prévio) }\end{array}$ \\
\hline $\begin{array}{l}\text { [O que pensa da } \\
\text { escola?] Eu penso que } \\
\text { essa escola é muito } \\
\text { boa. Ela ensina muitas } \\
\text { coisas que... por } \\
\text { exemplo muitas coisas }\end{array}$ & $\begin{array}{l}\text { A que vem esse lugar: } \\
\text { escola? }\end{array}$ & $\begin{array}{l}\text { Um lugar que serve para } \\
\text { passar saberes para } \\
\text { quem não os tem - ler, } \\
\text { escrever e um indefinido } \\
\text { "monte de coisas". }\end{array}$ & $\begin{array}{l}\text { A escola se propõe a } \\
\text { ensinar muita coisa, } \\
\text { mas muito do que se } \\
\text { aprendeu lá não foi } \\
\text { intenção da escola } \\
\text { ensinar (essa }\end{array}$ \\
\hline
\end{tabular}

${ }^{6}$ Lembrando que o todo do texto não é apresentado neste artigo por razões de espaço, mas cabe aqui dizer que esses trechos só fazem sentido se remetidos à entrevista como um todo, que o(a) autor(a) da pesquisa sempre terá em mãos. 


\section{pro.posıções}

e-ISSN 1980-6248

\begin{tabular}{|c|c|c|c|}
\hline $\begin{array}{l}\text { que a pessoa não sabe } \\
\text { a escola ensina. } \\
\text { Ensina a ler, a } \\
\text { escrever, ensina a } \\
\text { fazer um monte de } \\
\text { coisa. }\end{array}$ & & $\begin{array}{l}\text { Um lugar onde quem } \\
\text { sabe ensina quem não } \\
\text { sabe. } \\
\text { O texto traz um } \\
\text { discurso "oficial" sobre } \\
\text { o que é uma escola e } \\
\text { inclui uma avaliação da } \\
\text { instituição. }\end{array}$ & $\begin{array}{l}\text { observação decorre da } \\
\text { primeira leitura do } \\
\text { texto integra). }\end{array}$ \\
\hline $\begin{array}{l}\text { Eu gosto de ficar nos } \\
\text { projetos que tem na } \\
\text { escola, e eu não gosto } \\
\text { quando não tem aula. } \\
\text { Porque... na quinta- } \\
\text { feira passada não teve } \\
\text { aula porque a caixa } \\
\text { d'água estourou, aí } \\
\text { acabou a água, aí não } \\
\text { teve aula. }\end{array}$ & $\begin{array}{l}\text { O que induz a jovem a } \\
\text { ir à escola para os } \\
\text { projetos? } \\
\text { Que vivências escolhe } \\
\text { dizer para expressar o } \\
\text { que pensa da escola? } \\
\text { O que a faz não gostar } \\
\text { de se privar de vir à } \\
\text { escola? }\end{array}$ & $\begin{array}{l}\text { Projetos - dos quais se } \\
\text { pode participar } \\
\text { espontaneamente. Em } \\
\text { relação a estes expressa } \\
\text { seu prazer. } \\
\text { E não gosta quando não } \\
\text { tem aula. Prefere vir à } \\
\text { escola. }\end{array}$ & $\begin{array}{l}\text { Pesquisadores acham } \\
\text { curioso uma } \\
\text { adolescente que sente } \\
\text { prazer em ir à escola } \\
\text { devido a uma visão } \\
\text { prévia de que escola é } \\
\text { a priori difícil para } \\
\text { adolescentes. }\end{array}$ \\
\hline
\end{tabular}

Esse diálogo com as primeiras palavras do texto já traz ampliações para a compreensão do sentido da escola para a jovem: num primeiro momento, se refere à escola como um lugar no qual aqueles que sabem ensinam quem não sabe - uma visão "bancária", como diria Paulo Freire $(1987,1996)$, segundo a qual o aluno seria como um recipiente vazio a ser preenchido pelos saberes. O elemento novo na sua resposta é o da atração que a escola exerce ao oferecer projetos, dos quais os educandos podem espontaneamente participar. A disposição afetiva "gostar" aparece associada aos projetos. Fica a pergunta: “o que a faz não gostar de se privar de ir à escola?".

Quadro 2-Organização de um trecho de entrevista para análise

\begin{tabular}{|c|c|c|c|}
\hline $\begin{array}{c}\text { Falas da } \\
\text { entrevistada } \\
\text { (questões entre } \\
\text { colchetes) }\end{array}$ & $\begin{array}{l}\text { Interrogações de } \\
\text { sentido }\end{array}$ & $\begin{array}{c}\text { Possíveis respostas à } \\
\text { interrogação }\end{array}$ & $\begin{array}{c}\text { Impressões } \\
\text { (liberdade para } \\
\text { expressar o conflito } \\
\text { das novas } \\
\text { impressões com o } \\
\text { conhecimento } \\
\text { prévio) }\end{array}$ \\
\hline $\begin{array}{l}\text { [Quando não tem } \\
\text { projetos, o que você } \\
\text { costuma fazer?] } \\
\text { Quando não tem } \\
\text { projeto eu fico em } \\
\text { casa. Eu fico mexendo } \\
\text { no celular e ajudo a } \\
\text { minha mãe. Eu limpo } \\
\text { a casa, passo roupa, } \\
\text { faço tudo lá. Passo }\end{array}$ & $\begin{array}{l}\text { Quais as alternativas } \\
\text { de atividades fora do } \\
\text { período escolar? } \\
\text { Que responsabilidades } \\
\text { tem em casa a jovem? } \\
\text { Como a escola } \\
\text { aparece a partir de sua } \\
\text { vida doméstica? } \\
\text { Como se mostram as } \\
\text { tarefas domésticas? }\end{array}$ & $\begin{array}{l}\text { O texto trouxe os } \\
\text { afazeres de seu } \\
\text { cotidiano em casa, que } \\
\text { é preenchido por } \\
\text { tarefas domésticas e } \\
\text { uso do celular. É } \\
\text { responsável também } \\
\text { em casa. } \\
\text { A escola ocupa um } \\
\text { lugar em que, no seu }\end{array}$ & $\begin{array}{l}\text { Se estivesse } \\
\text { entrevistando um } \\
\text { menino, } \\
\text { possivelmente essa } \\
\text { questão não seria } \\
\text { trazida à tona! }\end{array}$ \\
\hline
\end{tabular}




\section{pro.posições}

$e$-ISSN 1980-6248

\begin{tabular}{|c|c|}
\hline $\begin{array}{l}\text { pano no chão, varro a } \\
\text { casa, cuido dos meus } \\
\text { irmãos. São três, } \\
\text { comigo quatro. É um } \\
\text { de } 4 \text { [anos], um de } 5 \text {, } \\
\text { um de } 10 \text {, e eu, de } 12 . \\
\text { E sou a única menina. }\end{array}$ & $\begin{array}{l}\text { cotidiano, centraliza } \\
\text { ofertas de lazer e } \\
\text { socialização, pois não } \\
\text { são lembradas outras } \\
\text { atividades fora da } \\
\text { escola, que são } \\
\text { apresentadas como } \\
\text { descrições, sem } \\
\text { avaliação positiva ou } \\
\text { negativa, como parte } \\
\text { da vida doméstica. Sua } \\
\text { condição de filha mais } \\
\text { velha e menina inclui } \\
\text { o cuidado com os } \\
\text { irmãos mais novos. }\end{array}$ \\
\hline
\end{tabular}

Pode-se afirmar que a escola é um lugar que a jovem gosta de frequentar preferivelmente em relação a outros, no caso, sua casa. Ao descrever seu cotidiano em casa, revelam-se muitas tarefas e responsabilidades - limpar a casa e cuidar dos irmãos menores -, que são apresentadas como parte de seu cotidiano, e deveres associados a seu gênero e idade. Escapar dessas tarefas pode levá-la a preferir a escola. A preferência pela escola tem também um componente de escape das tarefas domésticas e responsabilidades que tem como menina/mulher.

\section{Retomando as partes e o todo}

A partir do diálogo com as primeiras afirmações da jovem, a escola apareceu com mais significados do que apenas um lugar onde se transmitem conhecimentos àqueles que não os têm: é um lugar para realizar atividades livremente escolhidas e uma alternativa para sair dos deveres impostos a ela pela família, por ser menina e filha mais velha. As demais afirmações presentes no texto recebem esse mesmo tratamento; isto é, levantamos questões e propusemos respostas que resultam em um aprofundamento da compreensão inicial e possibilitam o aparecimento de aspectos ocultos à primeira vista.

$\mathrm{Na}$ realização dessa conversa hermenêutica com as partes, configuram-se agrupamentos que tratam de afirmações referentes a diferentes temas, ou começam a se formar novas partes, agora incluindo mais afirmações. Há, entretanto, um trânsito contínuo entre elas e o conjunto do texto. Trata-se do caráter circular da construção da compreensão, pois esta vai do todo para a parte, e desta para o todo. Uma compreensão que se formou no início da leitura sobre o que 


\section{pro.posıções}

http://dx.doi.org/10.1590/1980-6248-2018-0014

$e$-ISSN 1980-6248

o texto quis dizer deve ser substituída, na continuidade da leitura, pelas novas compreensões que se formam. Esse caminho deve ser todo registrado para que se possa realizar esse movimento de ir e vir entre o todo e as partes. Como diz Gadamer (2002b): "A tarefa é ampliar, em círculos concêntricos, a unidade do sentido compreendido" (p. 72), o que, como lembra esse autor, não é tarefa fácil, pois requer um diálogo contínuo com o texto, assim como entre suas partes e o todo, e a verificação dos projetos de sentido que se formam.

\section{Constelações: uma complementação da leitura do movimento parte/todo}

No processo de leituras e releituras, as partes reúnem-se em conjuntos de afirmações referentes a um mesmo tópico que aglutina as vivências, ou as "situações dadas" (Gegebenheiten), dados que "não são dados de experimentação e de medição, mas unidades de sentido" (Gadamer, 2002a, p. 124). Esses conjuntos denominamos de constelações, por analogia às constelações celestes.

Segundo informa Gleiser (2003, 9 de novembro), ver um grupo de estrelas como integrantes de uma constelação é um efeito que ocorre "porque, às vezes, as estrelas mais distantes são também as mais luminosas e aparentam estar mais perto do que na realidade estão" (p. 18). Também o movimento das estrelas é uma ilusão, já que quem se movimenta somos nós. "É importante refletirmos um pouco sobre onde estamos neste vasto Universo. A nossa visão do céu é produto dos vários movimentos da Terra" (Gleiser, 2003, 9 de novembro, p. 18). Aquilo que vemos como uma figura, por exemplo, uma cruz, é "uma ilusão, segundo a qual, acreditamos serem próximas estrelas que estão, na verdade, separadas por milhares de anosluz... O que percebemos da Terra é a projeção das estrelas no céu, que, na nossa perspectiva, aparenta ser uma cúpula bidimensional” (Szymanski, 2004, p. 3). Diferentes povos organizam o céu estrelado de diferentes maneiras. Os índios guaranis se orientam a partir de constelações chamadas “Tamanduá" ou "Pote de Mel”. Índios do Xingu nomeiam inclusive os vácuos, onde não se vê nenhuma estrela, e usam outros referenciais para se orientar pelas estrelas e definir seu calendário (Silva, 2003). Reconhecer que o agrupamento das partes do texto em constelações é resultado do lugar onde nos encontramos é importante para lembrar que toda compreensão é situada. A aglutinação das falas em conjuntos segue um critério subjetivo, como as constelações 


\section{pro.posições}

http://dx.doi.org/10.1590/1980-6248-2018-0014

$e$-ISSN 1980-6248

do firmamento olhadas pelas diferentes culturas, e é desejável esclarecer o que orientou a escolha das falas naquele conjunto.

Apresentaremos a seguir, como exemplo, o processo de construção de duas constelações, denominadas "Minha escola" e "Escola e gênero", e mostraremos como chegamos a elas. As falas referentes a essas constelações apareceram em vários momentos do texto, ao longo de toda a entrevista. Indicaremos no Quadro 3 o caminho percorrido até as constelações, utilizando o mesmo trecho da entrevista apresentado nos Quadros 1 e 2.

Quadro 3 - Construção dos elementos "minha escola" e "escola e gênero"

\begin{tabular}{|c|c|c|}
\hline $\begin{array}{c}\text { Falas da entrevistada } \\
\text { (questões entre colchetes) }\end{array}$ & Unidades de sentido & Constelações \\
\hline $\begin{array}{l}\text { [O que pensa da escola?] Eu } \\
\text { penso que essa escola é muito } \\
\text { boa. Ela ensina muitas coisas } \\
\text { que... por exemplo muitas } \\
\text { coisas que a pessoa não sabe a } \\
\text { escola ensina. Ensina a ler, a } \\
\text { escrever, ensina a fazer um } \\
\text { monte de coisa. }\end{array}$ & $\begin{array}{l}\text { Escola como lugar de ensino } \\
\text { Sentimento positivo em } \\
\text { relação à escola }\end{array}$ & "Minha escola" \\
\hline $\begin{array}{l}\text { Eu gosto de ficar nos projetos } \\
\text { que tem na escola, e eu não gosto } \\
\text { quando não tem aula. } \\
\text { Porque... na quinta-feira } \\
\text { passada não teve aula porque a } \\
\text { caixa d'água estourou, aí } \\
\text { acabou a água, aí não teve aula. }\end{array}$ & Projetos & \\
\hline $\begin{array}{l}\text { [Quando não tem projetos, o } \\
\text { que você costuma fazer?] } \\
\text { Quando não tem projeto eu } \\
\text { fico em casa. Eu fico mexendo } \\
\text { no celular e ajudo a minha } \\
\text { mãe. Eu limpo a casa, passo } \\
\text { roupa, faço tudo lá. Passo } \\
\text { pano no chão, varro a casa, } \\
\text { cuido dos meus irmãos. São } \\
\text { três, comigo quatro. É um de } \\
\text { 4, um de 5, um de 10, e eu, de } \\
\text { 12. E sou a única menina. }\end{array}$ & $\begin{array}{l}\text { Tarefas domésticas } \\
\text { Atividades de menina/mulher }\end{array}$ & "Escola e gênero" \\
\hline
\end{tabular}

Nesse pequeno trecho há várias unidades de sentido que, somadas a tantas outras provenientes das demais entrevistas que constituíram a pesquisa e de outros trechos dessa mesma entrevista, formaram duas constelações.

Outros aspectos que se iluminaram, após o diálogo com as várias constelações do texto, foram: o sentido dos projetos, o cotidiano de uma menina moradora da periferia de São Paulo, 


\section{pro.posıções}

http://dx.doi.org/10.1590/1980-6248-2018-0014

$e$-ISSN 1980-6248

a percepção de si mesma em relação aos outros, a relação meninos-meninas/meninas-meninas e as expressões da sexualidade nessa faixa etária. A compreensão prévia expandiu-se e trouxe à tona aspectos dos projetos desenvolvidos após o período das aulas, que se mostraram como alternativa cultural e de sociabilidade de grande importância para adolescentes desse território, além de um espaço libertador para as meninas presas às atividades domésticas. Essa compreensão expandida é resultado de um movimento de compreensão do todo para a parte e desta para o todo.

Uma vez constituídas as constelações, cabe a quem pesquisa realizar um diálogo entre elas e os autores de referência, ou seja, costurar sua compreensão do fenômeno que se revelou no processo de investigação com o conhecimento já produzido na área. A abertura, no caso desta pesquisa que investiga adolescentes no contexto escolar, sugere novas possibilidades para o agir educativo com adolescentes, que deve incluir considerações sobre gênero, autoridade, sexualidade, afetos no cotidiano escolar e modos de aprender e ensinar. Vemos que a ampliação da compreensão possibilitada pela hermenêutica nos permite lidar com a complexidade dos fenômenos humanos, trazendo à tona aquilo que não aparece a priori, sem o cuidado que a conversação com o texto pressupõe.

\section{Considerações finais}

Neste artigo procuramos mostrar como aspectos da fenomenologia existencial e da hermenêutica podem repercutir no trabalho científico de interpretação e análise e trazer suas contribuições para a construção de conhecimento nas áreas da psicologia e educação. Estamos cientes de que a proposta hermenêutica, mais especificamente tal como se pode entrever nos textos de Gadamer (2002a, 2002b), não pode ser vista como um conjunto de regras, ou como uma técnica para se interpretar textos (Hermann, 2003). Pudemos verificar, entretanto, que essa perspectiva interpretativa oferece um caminho orientador rigoroso para a compreensão de fenômenos humanos. O rigor dos procedimentos referenciados na hermenêutica reside no respeito a vorhabe, vorsicht e vorbegriff como pontos centrais no processo de compreensão. $O$ trânsito entre as partes e o todo, assim como a interrogação metódica pelo sentido em todos os momentos da análise, possibilita a contínua revisão de projetos prévios de compreensão. 


\section{pro.posıções}

http://dx.doi.org/10.1590/1980-6248-2018-0014

$e$-ISSN 1980-6248

A possibilidade de procedimento aqui apresentada não pretende oferecer um recurso impessoal, que pode ser repetido por qualquer pessoa em qualquer situação de análise. Caminhos foram sugeridos, e acreditamos que eles devem ser trilhados de um modo próprio pelos pesquisadores. As reflexões expostas, portanto, aproximam-se do sentido de techné, desenvolvido por Heidegger (2002), como "uma forma de desencobrimento" (p. 17) que resulta em uma criação, uma produção, e não na mera repetição despersonalizada. Isso, entretanto, não significa que os critérios de rigor dos procedimentos hermenêuticos deixem de ser respeitados.

O processo de interrogação pelo sentido que se levou a cabo na interpretação do depoimento de nossa pesquisa foi um modo de produzir um conhecimento. Trata-se de um modo de proceder em ciência diferente daqueles estabelecidos pelas ciências biológicas ou físicas, baseados no que Heidegger chama de pensamento calculador, os quais têm suas finalidades pré-determinadas, contam com determinados resultados e resultam em um pensar que "permanece sendo cálculo ainda quando não opera com números nem ponha em movimento máquinas de somar nem calculadoras" (p. 4). O pensamento reflexivo é uma possibilidade de construir conhecimento, não menos rigoroso. Aqueles que veem o pensamento calculador como modo único e hegemônico de construir o conhecimento entendem, muitas vezes, o pensar meditativo como inadequado para as questões práticas, como se ele acontecesse de modo espontâneo. Como lembra Heidegger (1994),

O pensar meditativo exige, por vezes, um esforço superior. Exige uma ampla preparação. Requer cuidados ainda mais delicados que qualquer outro ofício autêntico. Porém, do mesmo modo que o campônio, deve saber esperar que as sementes brotem e cheguem a amadurecer. (p. 5)

O caráter prismático dos fenômenos humanos no seu movimento de aparecer e ocultar, e o reconhecimento do que Critelli (1996) chama de "caráter de provisoriedade, mutabilidade e relatividade da verdade" (p. 11) requerem a contribuição de diferentes modos de pensar. Neste artigo, tentamos mostrar como o procedimento analítico inspirado pela fenomenologia existencial e hermenêutica pode ampliar o conhecimento de um determinado tema, abrindo espaço, inclusive, para que os questionamentos de quem pesquisa possam fazer parte da análise propriamente dita, e para que aquilo que comumente leva o nome de "resultado" seja sempre posto rigorosamente em dúvida e em perspectiva, em nome das inúmeras possibilidades de diálogo que o pensamento hermenêutico nos ensina a travar com outro interlocutor ou, mais especificamente, no processo de pesquisa. 


\section{pro.posıções}

$e$-ISSN 1980-6248

\section{Referências}

Bauer, M. W., \& Gaskell, G. (2013). Pesquisa qualitativa com texto, imagem e som (P. Guareschi, trad.). Petrópolis: Vozes.

Braga, T. B. M., Mosqueira, S. M., \& Morato, H. T. P. (2012). Cartografia clínica em plantão psicológico: Investigação interventiva num projeto de atenção psicológica em distrito policial. Temas em Psicologia, 20(2), 555-570.

Cabral, B. E., \& Morato, H. T. (2013). A questão de pesquisa como bússola: Notas sobre o processo de produção de conhecimento em uma perspectiva fenomenológica existencial. In C. L. B. T. Barreto, H. T. P. Morato, \& M. T. Caldas (Orgs.), Prática psicológica na perspectiva fenomenológica (pp. 159-182). Curitiba: Juruá.

Critelli, D. M. (1996). Analítica do sentido. São Paulo: Brasiliense.

Denzin, N. K., \& Lincoln, Y. S. (2006). Planejamento de pesquisa qualitativa: Teorias e abordagens. Porto Alegre: Artmed.

Flick, U. (2009). Introdução à pesquisa qualitativa (J. E. Costa, trad., Coleção Métodos de Pesquisa). São Paulo: Artmed.

Freire, P. (1987). Pedagogia do oprimido. Rio de Janeiro: Paz e Terra.

Freire, P. (1996). Pedagogia da autonomia. Rio de Janeiro: Paz e Terra.

Gadamer, H.-G. (2002a). Verdade e método: Traços fundamentais de uma hermenêutica filosófica (Vol. 1). São Paulo: Vozes.

Gadamer, H.-G. (2002b). Verdade e método: Complementos e indices (Vol. 2). São Paulo: Vozes.

Giorgi, A. (1985). Phenomenology and psychological research. Pittsburg: Duquesne University Press.

Gleiser, M. (2003, 9 de novembro). Um pouco sobre o céu [Caderno Mais]. Folha de S.Paulo, p. 18.

Grondin, J. (1999). Introdução à hermenêutica filosófica (B. Discbinger, trad.). São Leopoldo: Unisinos.

Grondin, J. (2003). Le tournant herméneutique de la phénoménologie. Paris: PUF. 


\section{pro.posıções}

http://dx.doi.org/10.1590/1980-6248-2018-0014

$e$-ISSN 1980-6248

Heidegger, M. (1994). Serenidad/Gelassenheit (Y. Zimmermann, trad.). Barcelona: Ediciones del Serbal.

Heidegger, M. (2008). Marcas do caminho (E. P. Giachini \& E. Stein, trad.). Petrópolis: Vozes.

Heidegger, M. (2012). Ser e tempo: Edição bilíngue (F. Castilho, trad.). Campinas: Editora da Unicamp.

Hermann, N. (2003). Hermenêutica e educação. Rio de Janeiro: DP\&A.

Houaiss, A. (2001). Dicionário Honaiss da língua portuguesa. Rio de Janeiro: Objetiva.

Lawn, C. (2007). Compreender Gadamer (H. M. Filho, trad.). Petrópolis: Vozes.

Ricoeur, P. (1978). O conflito das interpretações (J. Salomão, trad.). Rio de Janeiro: Imago.

Rohden, L. (2012). Hermenêutica filosófica: Entre Heidegger e Gadamer. Natureza Humana, 14(2), 14-36.

Silva, C. R. (2003). Relatório de pesquisa. Brasília: Funai/Unesco.

Szymanski, H. (2004). A prática reflexiva com famílias de baixa renda. In II Seminário Internacional de Pesquisa e Estudos Qualitativos: A pesquisa qualitativa em debate (pp. 1-7). Bauru: Sociedade de Estudos e Pesquisa Qualitativa.

Szymanski, H., \& Szymanski, L. (2014). O encontro reflexivo como prática psicoeducativa: Uma perspectiva fenomenológica. Educaşão, Ciência e Cultura, 19(1), 9-22.

Szymanski, L., Amaral, M., \& Badan, A. (no prelo). O adolescente e a escola. No prelo.

Submetido à avaliação em 9 de fevereiro de 2018; revisado em 25 de abril de 2018; aceito para publicaşão em 17 de maio de 2018. 